\title{
Notes on labeling and subject positions*
}

\author{
LUIGI RIZZI \\ University of Geneva, University of Siena \\ luigi.rizzi@unisi.it

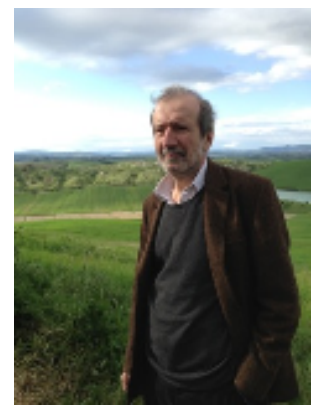 \\ "Dopo tanta strada percorsa insieme, è bello potersi voltare indietro, e subito dopo \\ tornare a guardare avanti. Come sempre, $g$ ".
}

The study of subject positions has illuminated different aspects of syntactic theory as well as the study of the interface with meaning and discourse. For instance, the analysis of the constraints on subject movement has nourished much research on locality, leading to various versions of the Empty Category Principle (Chomsky 1981) and to the subsequent study of freezing effects; and then the discovery that "free subject inversion" in Romance is in fact local movement of the thematic subject to a low focus position (Belletti 2001, 2004) has profoundly modified the study of the Null Subject Parameter (with consequences for the general conception of the parametric approach), and has contributed to establish the transparent view of the syntax - pragmatics interface which is congenial to cartographic studies. In this paper I would like to address some properties of subjects which interact in significant ways with a key ingredient of syntactic computations: the algorithm that assigns labels to the structures created by merge. I will first adopt a version of the approach proposed in Chomsky (2013), according to which the assignment of labels is essentially a matter of locality. The functioning of the system will be illustrated on the basis of the implementation proposed in Rizzi (2013), in connection with the fact that subjects typically must undergo movement and vacate the thematic position. This raises a "halting problem" for subject movement: under what conditions can it stop? Where does it have to stop, giving rise to a freezing configuration? Can freezing

\footnotetext{
* The related article will be part of Di Domenico, E., C. Hamann and S. Matteini (eds.) (to appear) Structures, Strategies and Beyond. Studies in Honour of Adriana Belletti, Amsterdam/Philadelphia, Benjamins Publishing Company.
}

CISCL- University of Siena

Adriana Belletti's Internet Celebration June, 2014 
effects on subjects be amenable to a "further explanation" in terms of fundamental computational ingredients such as labeling? This will lead us to address the properties of the different stopping points for subjects: the clause final low focus position, which will be shown to give rise to observable freezing effects, and the canonical, clause initial position, giving rise to familiar that-trace type effects which are also amenable to forms of freezing. The final part of the paper will be devoted to the proper categorial status of the head responsible for the "subject criterion", in an attempt to capture the case of "quirky" subjects with psych-verbs (Belletti \& Rizzi 1988). This will lead to a discussion of different kinds of strategies to avoid the freezing effects and make further subject movement possible. A brief outline of the general consequences of the labeling approach for the movability of complements and specifiers will conclude the paper.

\section{References}

Belletti, A. (2001) Inversion as focalization. In A.Hulk \& J.Y.Pollock (Eds.) Subject Inversion in Romance and the Theory of Universal Grammar, (pp 60-90). New York: Oxford University Press.

Belletti, A. (2004) Aspects of the Low IP Area. In The Structure of CP and IP: The Cartography of Syntactic Structures, Vol. 2, L. Rizzi (Ed). New York: Oxford University Press.

Belletti, A. and Rizzi L. (1988) Psych-verbs and theta-theory. Natural Language and Linguistic Theory 6, 291-352.

Chomsky, N. (1981) Lectures on Government and Binding. Dordrecht: Foris Publications.

Chomsky, Noam. (2013) Problems of Projection. In Lingua, 130, Special Issue "Core Ideas and Results in Syntax", 33-49.

Rizzi, L. (2014) “Cartography, Criteria, and Labeling”, ms., University of Geneva, University of Siena. 